\title{
Dental Fear and Dental Health and Attendance among Finnish Male Prisoners
}

\author{
Raija Vainionpää ${ }^{1,3}$, Paula Pesonen², Marja-Liisa Laitala1, Vesa Pohjola ${ }^{2,3}$, Vuokko Anttonen ${ }^{1,3}$ \\ ${ }^{1}$ Research Unit of Oral Health Sciences, Department of Cariology, Endodontology and Paediatric Dentistry, University of \\ Oulu, Finland. \\ ${ }^{2}$ Research Unit of Oral Health Sciences, University of Oulu, Finland. \\ ${ }^{3}$ Medical Research Centre, Oulu University Hospital and University of Oulu, Finland.
}

\author{
Corresponding Author: \\ Raija Vainionpää \\ University of Oulu \\ P.O. Box 5281, FI-90014 University of Oulu \\ Finland \\ Phone: +358405949985 \\ E-mail: raija.vainionpaa@pp.inet.fi
}

\begin{abstract}
Objectives: The aim of the present study was to evaluate the prevalence of dental fear and the associations between dental fear and dental health and dental attendance among Finnish prisoners.

Material and Methods: Eighty-nine voluntary male prisoners from the Pelso Prison participated in this cross-sectional clinical study between September 2014 and February 2015. Forty-six (51.7\%) of them were also interviewed for their background factors, dental fear and dental attendance. To evaluate the prisoners' level of dental fear, the Modified Dental Anxiety Scale and Dental Visual Analogue Scale were used. The numbers of decayed, missing, filled and remaining teeth reported dental health. For analyses Pearson's Chi-square test, Fisher's exact test, logistic regression analyses and the independent samples Kruskall-Wallis test were conducted.

Results: Among male prisoners four out of 46 (8.7\%) reported severe and fourteen out of $46(30.4 \%)$ moderate dental fear, $60.9 \%$ had mild or no dental fear. Those with no dental fear visited a dentist regularly more often than those with dental fear. The use of snuff and number of medications were positively associated with severe dental fear.

Conclusions: Dental fear is common among Finnish male prisoners. High number of prescribed medications, use of snuff and irregular dental attendance may indicate severe dental fear among Finnish male prisoners.
\end{abstract}

Keywords: dental anxiety; odontophobia; dental fear; delivery of dental care; prisoners.

\author{
Accepted for publication: 23 December 2019 \\ To cite this article: \\ Vainionpää R, Pesonen P, Laitala ML, Pohjola V, Anttonen V. \\ Dental Fear and Dental Health and Attendance among Finnish Male Prisoners \\ J Oral Maxillofac Res 2019;10(4):e4 \\ URL: http://www.ejomr.org/JOMR/archives/2019/4/e4/v10n4e4.pdf \\ doi: $\underline{10.5037 / j o m r .2019 .10404}$
}




\section{INTRODUCTION}

Dental fear is among the four most common fears in adult populations and the prevalence of it varies depending on the population, country and its culture as well as the scales, indicators and criteria used. Dental fear of some degree has been reported occurring from 4 to $42 \%$ of adults $[1,2]$. The aetiology of dental fear is multifactorial. Female gender, young age, low education and low socioeconomic status, as well as smoking are often associated with dental fear [3-5]. Adults who are afraid of dental treatment have been reported having poorer dental health compared with people with low or no dental fear at all $[\underline{6}, \underline{7}]$. Furthermore, people with dental fear tend to attend dental care irregularly, or to avoid it completely $[\underline{7}, \underline{8}]$. The literature about dental fear among prisoners is scarce, even though prisoners are known to possess many of the factors associated with dental fear. They are a group of people with poor oral health [9] and with many health problems, including the alcohol and drug use disorders and use of tobacco products are prevalent $[10]$. Among prisoners there are high levels of psychiatric morbidity and regular use of medicine is common [11]. Prisoners' education level is low [12] and reading and writing problems are common [13]. Most prisoners visit the dentist rarely and irregularly in their civil life and in prison [14].

Due to the lack of scientific evidence, the aim of this study was to evaluate the prevalence of dental fear among Finnish prisoners by using dental fear scales. Another aim was to evaluate the association of dental fear with dental health, health behaviours and dental attendance among them. It was hypothesised that the prevalence of dental fear is high among Finnish prisoners and prisoners with dental fear have poorer dental health than prisoners without dental fear. It was also hypothesised that dental fear associates with dental health, dental health behaviours and attendance.

\section{MATERIAL AND METHODS}

The expression 'dental fear' was used here to cover all different aspects of fear related to dental treatment e.g. dental fear, anxiety, and even severe fear even though these concepts are not the same. The data collection was conducted between September 2014 and February 2015.

\section{Participants}

All the prisoners incarcerated in the Pelso Prison,
Vaala, Finland were invited to participate in this crosssectional clinical study. The Pelso Prison is a closed prison and at the time of study there were facilities for 110 prisoners (including 11 female prisoners). In total 100 voluntary prisoners participated in the study. Some prisoners were transferred to another prison or were released during the study and some either ignored or refused the invitation for the study. The reasons for refusal were e.g. "Not having time for this" or "Not interested". Details of the prisoners' sentences were not available for the research group, but in general, there are more sentenced than remand prisoners in the Pelso Prison.

Male prisoners comprised $89 \%(n=89)$ of the 100 clinically examined participants. About half of the men were interviewed $(n=46)$ (convenience sample). All the 11 female participants were clinically examined and 4 of them were interviewed. Due to the limited number of female participants, they were excluded from the analyses.

The data of males from both the clinical examinations $(n=89)$ and the interviews $(n=46)$ comprised the material for the present study.

\section{Interview}

Because of a time limit, out of the 89 male prisoners who were clinically examined, 46 first ones were invited for a face-to-face interview as for their background factors, and for health behaviours and for their dental attendance. Because some prisoners had literacy problems, assistance was performed for filling the questionnaires out. Validation for the questionnaires has been done previously 1 15. The interview took place in the dental office of the prison premises during separate dental appointments and was carried out by RV (working as a dentist at the Pelso Prison). Structured questionnaires were used with the one-on-one oral motivational interviewing technique (www.motivationalinterview.org). Every interview lasted 90 minutes.

\section{Background factors, health behaviours and dental attendance}

The participants' age (years) and gender were available from prisoners' records, the education level was asked (compulsory education of 9 years/ vocational school/matriculation exam). Medicines regularly used by the prisoners were obtained from their medical files (number and type of prescribed medicines).

Current smoking and the use of snuff and illicit drugs and alcohol consumption in civil life were surveyed 
with the questions "Do you smoke": no/1 - 20 cigarettes daily/more than 20 cigarettes daily?" and "Have you used snuff in civil life (yes/no)?"The snuff sale is prohibited in Finland although it is illegally imported from other Nordic countries, particularly from Sweden. "Have you used illicit drugs in civil life: (yes/no)?", "Have you used alcohol in civil life: no/twice a month or less frequently/once a month/ every other week/once a week/more than once a week."

Regularity of dental attendance was determined with the question: "How often do you visit a dentist?" with the following three response alternatives: only when I have pain or other problems (indicating emergency care)/regularly for check-ups (indicating regular care)/never. In addition, the reasons for dental fear were asked as follows: "In your opinion, what are the reasons for your dental fear?" (Painful or difficult experiences of previous dental care/Bad experiences in the dental care of your relatives or friends/Extensive treatment need/General health or psychological problems/Poor behaviour by dental personnel). Further, the prisoners were asked if nitrogen oxide or conscious oral sedation had been used previously for dental fear with the respond alternatives (Yes/No).

\section{Dental fear forms}

To assess dental anxiety, the Modified Dental Anxiety Scale (MDAS) was used [16,17]. MDAS comprises five multiple-choice questions regarding the respondent's level of anxiety in the specific dental situations. The response alternatives range from 1 (not anxious) to 5 (extremely anxious). Sum scores for these five questions range from 5 to 25 and provide the overall level of dental anxiety. It is commonly and also here, categorised as follows: $<10$ (not anxious at all), 10 - 18 (moderately anxious) and $\geq 19$ (extremely anxious).

The respondents were also asked to fill in a Dental Visual Analogue Scale (DVAS) form to estimate the severity and intensity of their fear in terms of 18 dental procedures and situations [18]. The prisoners were asked to mark (assisted, if needed) their current level of dental fear on a $10 \mathrm{~cm}$ dotted line. Score 0 indicated "no fear at all" and score 10 indicated "the worst imaginable fear".

\section{Clinical examination}

One trained and calibrated examiner (RV) performed all the clinical examinations in the fully equipped dental office of the Pelso Prison. In this study, caries findings were recorded per tooth based on the International Caries Detection and Assessment System (ICDAS) criteria and activity estimation. The cut-off point for the decayed lesion (D) was ICDAS active 3. The number of decayed (D), missed (M) and restored/filled teeth (F), and DMFT was also recorded. The $\mathrm{T}$ values were dichotomised as $<23$ and the rest, the $\mathrm{D}$ values as $<5$ and the rest, the $\mathrm{M}$ values as $<5$ and the rest, the $F$ values as $<6$ and the rest, and the DMFT values as $<16$ and the rest, according to the distribution of the T, D, M, F and DMFT values in the study population. If at least one lesion was clinically observed to extend into the dentin, a bitewing radiograph was taken, and the information was included in the clinical findings. For the validity of the clinical examinations, the intra-examiner and inter-examiner agreements were investigated by calculating kappa values $(\kappa)$. Because there was only one examiner, the parallel examination by the golden standard was done at the baseline and repeated after two months. Vainionpää et al. [0] have previously described the clinical examination process and the training and calibration protocol in detail.

\section{Statistical analysis}

The mean and standard deviation (M [SD]) values for MDAS and DVAS variables were calculated. For the analyses, the MDAS scores were also categorised as follows: 5 - 9 (no dental fear), 10 - 18 (moderate dental fear) and $\geq 19$ (severe dental fear). With respect to dental attendance, the Emergency care and Never alternatives were categorised as irregular attendance. Dental health was recorded as frequencies and median values (min, max) for remaining (T), decayed (D), missing (M), and restored/filled teeth (F). DMFT values were also calculated. Cut-off point 4 or more medicines was used for prescribed medications. Participants were divided into nonsmokers, smokers (1 - 20 cigarettes/day) and heavy smokers (more than 20 cigarettes/day). Eventually, for the analysis they were dichotomized to yes/no. As for alcohol consumption, it was divided to sober ones (no), moderate consumers (twice a month or less frequently; once a month; every other week; once a week) and major consumers (more than once a week) and finally this was dichotomized to yes/no.

To compare dental health variables between MDAS classes the independent samples Kruskall - Wallis test was used.

The significance of the association between categorised MDAS and the dental health as well as the background variables was analysed by using cross 
tabulation with the Chi-square or Fisher's exact test if the assumptions of the Chi-square test were not fulfilled.

A stepwise logistic regression model (by excluding variables from the model one by one on the grounds of their $\mathrm{P}$ value) was performed by using severe dental fear as the dependent variable and age, education level, DMFT, smoking, use of snuff, alcohol consumption, and use of drugs as well as medications and dental attendance as explanatory variables. The outcome was presented as odds ratio with $95 \%$ confidence interval. Goodness of fit was tested with the Hosmer and Lemeshow test. All the statistical analyses were performed by using the SPSS (version 24.0, Inc., Chicago, Illinois, USA). The $\mathrm{P}$ values lower than 0.05 represented statistical significance.

\section{Ethical approval}

Participation was voluntary, but all the prisoners in the Pelso Prison, Finland, were provided with the same opportunity to participate. All the participants gave their written informed consent for the study. The Criminal Sanctions Agency and the Ethical Committee of the Northern Ostrobothnia Hospital District gave their approval for the study (EETTMK: 50/2014).

\section{RESULTS \\ Dental fear}

Four out of 46 prisoners $(8.7 \%)$ had severe and fourteen out of $46(30.4 \%)$ moderate dental fear.
MDAS was 10.2 (5.61). The most fear-inducing dental procedures were the extractions of teeth (DVAS $4.2 / 10[3.93] \mathrm{cm}$ ) and root canal treatment (DVAS $3.7 / 10[3.52] \mathrm{cm}$ ), as well as pain in general (DVAS mean 3.6/10 [2.89] $\mathrm{cm}$ ). Taking a dental radiograph was considered the least frightening dental procedure (DVAS 0.5/10 [1.28] cm), followed by applying filling material (DVAS 0.6/10 [0.91] cm).

In the opinion of the prisoners with dental fear (MDAS $\geq 10, \mathrm{n}=18$ ) the most common cause for their dental fear was previous painful or difficult experiences (12 out of $18,67 \%)$. Other causes were previous extensive dental treatments (5 out of 18 , $28 \%$ ) and "poor" attitude by dental personnel ( 2 out $18,11 \%)$ as well as indirect causes such as stories of poor dental experiences by relatives or friends ( 2 out of $18,11 \%$ ) Two prisoners reported general health problems as the cause for dental fear.

\section{Oral health and health behaviours}

Almost all needed restorative treatment (85\%). None of the prisoners was edentulous. Participants with no dental fear (MDAS < 10) had more restored/filled teeth than the rest of the study population $(\mathrm{P}=0.034)$ (Table 1). Of the smokers, almost $45 \%$ had at least moderate fear, MDAS $\geq 10$. There were a few nonsmokers $(n=6[13] \%)$ and they all had a low MDAS score $(<10)$. Seven out of ten prisoners who reported using snuff reported moderate or severe dental fear more often than nonusers $(P=0.033)$ (Table 2). Before imprisonment $59 \%$ had used illicit drugs and $76 \%$ were alcohol consumers, however there was no association between use of drugs and alcohol consumption and dental fear.

Table 1. Median, minimum, and maximum values of remaining (T), decayed (D), missing (M) and filled teeth (F), as well as DMFT according categorized MDAS scores among Finnish male prisoners $(\mathrm{n}=46)$

\begin{tabular}{|c|c|c|c|c|c|}
\hline \multirow{3}{*}{$\begin{array}{l}\text { MDAS } \\
\text { N (\%) }\end{array}$} & \multicolumn{5}{|c|}{ Variable } \\
\hline & \multicolumn{5}{|c|}{ Median $(\min / \mathbf{m a x})$} \\
\hline & $\mathbf{T}$ & D & $\mathbf{M}$ & $\mathbf{F}$ & DMFT \\
\hline \multicolumn{6}{|l|}{$<10$} \\
\hline $28(60.9)$ & $26(7 / 32)$ & $3.5(0 / 25)$ & $6(0 / 25)$ & $8.5(0 / 22)$ & $22(3 / 32)$ \\
\hline \multicolumn{6}{|l|}{$10-18$} \\
\hline $14(30.4)$ & $27(6 / 32)$ & $2(0 / 10)$ & $5(0 / 26)$ & $3(0 / 11)$ & $14(1 / 30)$ \\
\hline \multicolumn{6}{|l|}{$\geq 19$} \\
\hline $4(8.7)$ & $26.5(18 / 29)$ & $10(1 / 16)$ & $5.5(3 / 14)$ & $4.5(4 / 10)$ & $21.5(9 / 24)$ \\
\hline $\mathbf{P}$ & 0.736 & 0.157 & 0.736 & $0.034^{\mathrm{a}}$ & 0.07 \\
\hline Total & $26(6 / 32)$ & $3(0 / 25)$ & $6(0 / 26)$ & $7(0 / 22)$ & $17.5(1 / 32)$ \\
\hline
\end{tabular}

aP $<0.05$, Kruskall-Wallis test.

MDAS = Modified Dental Anxiety Scale; DMFT = decayed, missing, or filled permanent teeth; $\mathrm{N}=$ number of male participants.

MDAS < 10: no dental fear, 10 - 18: moderate dental fear, $\geq 19$ : severe dental fear. 
Table 2. Distribution of male participants according to their dental fear (MDAS), dental health, background factors and dental attendance

\begin{tabular}{|c|c|c|c|c|c|}
\hline \multirow{2}{*}{\multicolumn{2}{|c|}{$\begin{array}{c}\text { Variable } \\
\text { N }(\%)\end{array}$}} & \multicolumn{4}{|c|}{ MDAS, male, $n=46$} \\
\hline & & \multirow{2}{*}{$\begin{array}{c}<10 \text { N (\%) } \\
28(60.9) \\
10(35.7)\end{array}$} & \multirow{2}{*}{$\begin{array}{c}\geq 10 \mathrm{~N}(\%) \\
\mathbf{1 8 ( 3 9 . 1 )} \\
6(33.3)\end{array}$} & \multirow{2}{*}{$\begin{array}{c}\begin{array}{c}\text { Total } \\
\text { N (\%) }\end{array} \\
16(34.8)\end{array}$} & \multirow{3}{*}{$\begin{array}{r}\text { P value } \\
0.869^{\mathrm{a}}\end{array}$} \\
\hline \multirow{2}{*}{$\mathbf{T}$} & $0-23$ & & & & \\
\hline & $\geq 24$ & $18(64.3)$ & $12(66.7)$ & $30(65.2)$ & \\
\hline \multirow{2}{*}{ D } & $0-4$ & $15(53.6)$ & $12(66.7)$ & $27(58.7)$ & \multirow{2}{*}{$0.379^{\mathrm{a}}$} \\
\hline & $\geq 5$ & $13(46.4)$ & $6(33.3)$ & $19(41.3)$ & \\
\hline \multirow{2}{*}{$\mathbf{M}$} & $0-5$ & $12(42.9)$ & $9(50)$ & $21(45.7)$ & \multirow{2}{*}{$0.635^{\mathrm{a}}$} \\
\hline & $\geq 6$ & $16(57.1)$ & $9(50)$ & $25(54.3)$ & \\
\hline \multirow{2}{*}{$\mathbf{F}$} & $0-6$ & $9(32.1)$ & $13(72.2)$ & $22(47.8)$ & \multirow{2}{*}{$0.008^{\mathrm{a}, \mathrm{c}}$} \\
\hline & $\geq 7$ & $19(67.9)$ & $5(27.8)$ & $24(52.2)$ & \\
\hline \multirow{2}{*}{ DMFT } & $0-15$ & $8(28.6)$ & $10(55.6)$ & $18(39.1)$ & \multirow{2}{*}{$0.067^{\mathrm{a}}$} \\
\hline & $\geq 16$ & $20(71.4)$ & $8(44.4)$ & $28(60.9)$ & \\
\hline \multirow{2}{*}{ Age } & $<35$ & $14(50)$ & $13(72.2)$ & $27(58.7)$ & \multirow{2}{*}{$0.135^{\mathrm{a}}$} \\
\hline & $\geq 35$ & $14(50)$ & $5(27.8)$ & $19(41.3)$ & \\
\hline \multirow{2}{*}{ Education } & Compulsory & $13(46.4)$ & $12(66.7)$ & $25(54.3)$ & \multirow{2}{*}{$0.179^{\mathrm{a}}$} \\
\hline & Vocational/gymnasium & $15(53.6)$ & $6(33.3)$ & $21(45.7)$ & \\
\hline \multirow{2}{*}{ Smoking } & Yes & $22(78.6)$ & $18(100)$ & $40(87)$ & \multirow{2}{*}{$0.068^{\mathrm{b}}$} \\
\hline & No & $6(21.4)$ & 0 & $6(13)$ & \\
\hline \multirow{2}{*}{ Snuff } & Yes & $3(10.7)$ & $7(38.9)$ & $10(21.7)$ & \multirow{2}{*}{$0.033^{b, c}$} \\
\hline & No & $25(89.3)$ & $11(61.1)$ & $36(78.3)$ & \\
\hline \multirow{2}{*}{ Alcohol } & Yes & $21(75)$ & $14(77.8)$ & $35(76.1)$ & \multirow{2}{*}{ n.s. } \\
\hline & No & $7(25)$ & $4(22.2)$ & $11(23.9)$ & \\
\hline \multirow{2}{*}{ Drug } & Yes & $15(53.6)$ & $12(66.7)$ & $27(58.7)$ & \multirow{2}{*}{$0.379^{\mathrm{a}}$} \\
\hline & No & $13(46.4)$ & $6(33.3)$ & $19(41.3)$ & \\
\hline \multirow{2}{*}{ Dental attendance } & Regular & $8(28.6)$ & 0 & $8(17.4)$ & \multirow{2}{*}{$0.015^{\mathrm{b}, \mathrm{c}}$} \\
\hline & Irregular & $20(71.4)$ & $18(100)$ & $38(82.6)$ & \\
\hline \multirow{2}{*}{ Medicines } & $\leq 4$ & $18(64.3)$ & $8(44.4)$ & $26(56.5)$ & \multirow{2}{*}{$0.185^{\mathrm{a}}$} \\
\hline & $>4$ & $10(35.7)$ & $10(55.6)$ & $20(43.5)$ & \\
\hline
\end{tabular}

aPearson Chi-Square, ${ }^{\mathrm{b}}$ Fisher's exact test, ${ }^{\mathrm{c}} \mathrm{P}<0.05$.

MDAS = Modified Dental Anxiety Scale; DMFT = decayed, missing, or filled permanent teeth; $\mathrm{T}=$ remaining; $\mathrm{D}=\mathrm{dec}$ eyed; $\mathrm{M}=$ missing; $\mathrm{F}=$ restored/filled teeth; $\mathrm{N}=$ number of male participants; n.s. = nonsignificant.

Irregular dental attendance was more often reported by those with moderate or severe dental fear (MDAS $\geq 10$ ) than by those with no dental fear (MDAS $<10$ ) $(\mathrm{P}=0.015)$ (Table 2$)$. Thirty-eight prisoners $(83 \%)$ reported visiting a dentist only when they had pain or other problems. Seven respondents $(15 \%)$ reported having never visited a dentist, but still three of them reported having dental fear (MDAS $\geq 10$ ). Nitrogen oxygen had been used in one case for dental fear. Six out of the seven respondents, who had been given conscious oral sedation in dental care, had dental fear $(\mathrm{MDAS} \geq 10)(\mathrm{P}=0.01)$.

Of the respondents $84 \%$ had regular prescribed medicines, antipsychotics $(60 \%)$ being the most common followed by analgesics $(48 \%)$. Nearly half $(44 \%)$ of the respondents had four or more prescribed medicines, of which about two-thirds $(70 \%)$ were antipsychotics. According to multivariate logistic regression analyses (Table 3), those using snuff or using four or more prescribed medicine were more likely to have severe dental fear than those not using snuff or using three or less prescribed medicines.

Table 3. The association between severe dental fear and independent variables in an adjusted logistic regression model

\begin{tabular}{l|c|c|c|c}
\hline \multirow{2}{*}{ Variable } & \multirow{2}{*}{ Odds ratio } & \multicolumn{2}{|c|}{$\begin{array}{c}\mathbf{9 5 \%} \text { confidence } \\
\text { interval }\end{array}$} & \multirow{2}{*}{$\begin{array}{c}\text { P } \\
\text { value }\end{array}$} \\
\cline { 3 - 4 } & & Lower & Upper & \\
\hline Medicines & 5.3 & 1.07 & 25.84 & 0.042 \\
\hline Snuff & 12.9 & 1.87 & 88.87 & 0.009 \\
\hline
\end{tabular}

Goodness of fit $\chi^{2}=4.4, \mathrm{P}=0.353 . \mathrm{R}^{2}=0,255$.

Medicines: cut-off point 4 or more.

Use of snuff: no, yes. 


\section{DISCUSSION}

As hypothesised, dental fear was more common among Finnish male prisoners than among their agematched peers in the general population. In their study on a group of Finnish citizens aged 30 years or older $(\mathrm{n}=6.335)$, Pohjola et al. [19] reported that $6.2 \%$ of men have severe and $22.9 \%$ moderate dental fear, while $70.9 \%$ of men did not report any dental fear. In the present study, the prevalence of dental fear is higher than that; the frequencies here are $8.7 \%, 30.4 \%$, and $60.9 \%$, respectively. However, the prevalence is lower than in the previous study by Heidari et al. [14]. They reported that $59 \%$ of the male prisoners $(n=122)$ avoided dental treatment because of dental anxiety. Prisoners' dental fear is associated with the high number of prescribed medications and the use of snuff as well as poor dental health and use of mainly emergency dental care.

Studies have shown that prisoners' oral health is poor $[9,14]$. This was also true in the present study; the oral health of prisoners was poor with or without dental fear. Previous studies have shown that individuals with dental fear have more need for dental care $[\underline{6}, \underline{20}]$ than those without, which association was not demonstrated in the present study.

In the present study, despite their young age, almost all had prescribed regular medications, antipsychotics being the most common pharmaceuticals especially among those with many prescribed medications. In fact, antipsychotics are prescribed for the two most common diagnoses among Finnish prisoners: recreational drug abuse and personality disorders. The high prevalence of drug abuse among the participants may have impacted on their dental fear, irregular dental attendance patterns, as well as poor oral health [21]. Four or more prescribed medicines are known to be a risk for hyposalivation [22], which again may be a risk for future dental decay in the present study population. The number of medications was associated with severe dental fear in this study, which causes an additional threat for oral health.

In earlier studies dentally fearful have been more likely than the others to have the diagnoses of psychological disorders e.g. anxiety disorders, behavioural problems, mood disorders, conduct disorders, alcohol and substance abuse problems, and the social phobia $[\underline{23}, 24]$, which all are common in prison populations [25]. Since almost all (94\%) prisoners in Finland have psychiatric diagnose [26], their psychiatric status may be associated with dental fear. This could not be studied here but should be taken into consideration in dental care.
In the previous studies [27], smoking has been associated with dental fear. Here the use of snuff instead of smoking was associated with dental fear. This is most likely since prisoners here are a homogenous group with poor health behaviours: almost all smoke, but not all use snuff. However, all snuff users smoked. Use of snuff, on the other hand, is not associated with dental caries, whereas smoking is [28].

Prisoners are in general and here, afraid of painful dental procedures. In addition, the fear of dental procedures (DVAS) followed here the pattern reported earlier by those treated under dental general anaesthesia [29], although the study population of this study was somewhat different in comparison with this present here.

The literature on dental fear among prisoners is to our knowledge scarce, which increases the value of the present study. Another strength is that 89 $(80.9 \%)$ men out of the total 110 during the study period volunteered for participating in the clinical examination and half of them to the interview. Learning difficulties were expressed as disability to fill out the forms and understand the questions. To ensure that the respondents understood the questions and options correctly, the dentist (RV) interviewed using the motivational interviewing technique and assisted when needed participants. Conducting the interviews in this manner instead of asking the participants to fill questionnaires may also have helped to reveal even the most difficult issues concerning the prisoners' fears and health behaviours. In fact, the general attitude of the prisoners towards this study was positive, with only a few exceptions. Another strength of this study is the use of the structured forms (MCDS, DVAS) to measure dental fear.

The relatively small number of participants may cause bias. Secondly present study focused only on male prisoners from one prison and therefore generalization cannot be made, and the results must be interpreted with caution. In future studies, a multi-prison study is needed to obtain a larger sample size.

\section{CONCLUSIONS}

The studies on this topic in literature is scarce, and no studies on dental fear among prisoners, exist to our knowledge in Finland, not to mention its association with dental health. The study investigating a delicate subject in a marginalized study population benefitted from using motivational interviewing technique. The results indicate that dental fear is 
more common among Finnish male prisoners than general population. Due to reasons not studied here, the prisoners tend to use only emergency dental care or not use dental care at all both in civil life and in the prison. Despite their young age, prisoners use many medicines and frequently use psychoactive substances: smoke, use drugs, snuff and alcohol. Use of several medications and the use of snuff have the strongest association with severe dental fear. These facts can and should be considered in the dental treatment of prisoners.

\section{ACKNOWLEDGMENTS AND DISCLOSURE STATEMENTS}

We want to express our gratitude to the personnel and prisoner in the Pelso Prison.

The authors report no conflicts of interest related to this study.

No external funding apart from the support of the author's institutions (MRC Oulu University Hospital and University of Oulu), was available for this study.

\section{REFERENCES}

1. Oosterink FM, de Jongh A, Hoogstraten J. Prevalence of dental fear and phobia relative to other fear and phobia subtypes. Eur J Oral Sci. 2009 Apr;117(2):135-43. [Medline: 19320722] [doi: 10.1111/j.1600-0722.2008.00602.x]

2. Carter AE, Carter G, Boschen M, AlShwaimi E, George R. Pathways of fear and anxiety in dentistry: A review. World J Clin Cases. 2014 Nov 16;2(11):642-53. [Medline: 25405187] [PMC free article: 4233415] [doi: 10.12998/wjcc.v2.i11.642]

3. Yildirim TT. Evaluating the Relationship of Dental Fear with Dental Health Status and Awareness. J Clin Diagn Res. 2016 Jul;10(7):ZC105-9. [Medline: 27630944] [PMC free article: 5020232] [doi: 10.7860/JCDR/2016/19303.8214]

4. Svensson L, Hakeberg M, Boman UW. Dental anxiety, concomitant factors and change in prevalence over 50 years. Community Dent Health. 2016 Jun;33(2):121-6. [Medline: 27352466]

5. Armfield JM, Spencer AJ, Stewart JF. Dental fear in Australia: who's afraid of the dentist? Aust Dent J. 2006 Mar;51(1): 78-85. [Medline: 16669482] [doi: 10.1111/j.1834-7819.2006.tb00405.x]

6. Schuller AA, Willumsen T, Holst D. Are there differences in oral health and oral health behavior between individuals with high and low dental fear? Community Dent Oral Epidemiol. 2003 Apr;31(2):116-21. [Medline: 12641592] [doi: $10.1034 / j .1600-0528.2003 .00026 . x$ ]

7. Saatchi M, Abtahi M, Mohammadi G, Mirdamadi M, Binandeh ES. The prevalence of dental anxiety and fear in patients referred to Isfahan Dental School, Iran. Dent Res J (Isfahan). 2015 May-Jun;12(3):248-53. [Medline: 26005465] [PMC free article: 4432608]

8. Pohjola V, Lahti S, Vehkalahti MM, Tolvanen M, Hausen H. Association between dental fear and dental attendance among adults in Finland. Acta Odontol Scand. 2007 Aug;65(4):224-30. [Medline: 17762985] [doi: 10.1080/00016350701373558]

9. Vainionpää R, Peltokangas A, Leinonen J, Pesonen P, Laitala ML, Anttonen V. Oral health and oral health-related habits of Finnish prisoners. BDJ Open. 2017 Mar 3;3:17006. [Medline: 29607077] [PMC free article: 5842830] [doi: 10.1038/bdjopen.2017.6]

10. Fazel S, Yoon IA, Hayes AJ. Substance use disorders in prisoners: an updated systematic review and meta-regression analysis in recently incarcerated men and women. Addiction. 2017 Oct;112(10):1725-1739. [Medline: 28543749] [PMC free article: 5589068 ] [doi: $10.1111 /$ add.13877]

11. Viitanen P, Vartiainen H, Aarnio J, Von Gruenewaldt V, Hakamäki S, Lintonen T, Mattila AK, Wuolijoki T, Joukamaa M. Finnish female prisoners - heavy consumers of health services. Scand J Public Health. 2013 Jul;41(5):479-85. [Medline: 23456680] [doi: 10.1177/1403494813479215]

12. Hetland H, Eikeland OJ, T Manger, Diseth $\AA$, Asbjørnsen A. Educational background in a prison population. J Correct Educ. 2007 Jun;58(2):145-56. [URL: https://www.jstor.org/stable/23282733]

13. Tuominen T, Korhonen T, Hämäläinen H, Temonen S, Salo H, Katajisto J, Lauerma H. Functional illiteracy and neurocognitive deficits among male prisoners: implications for rehabilitation. J Forens Pract. 2014 Nov;16(4):268-80. [doi: 10.1108/JFP-10-2013-0044]

14. Heidari E, Dickinson C, Fiske J. An investigation into the oral health status of male prisoners in the UK. J Disabil Oral Health. 2008;9(1):3-12.

15. Anttonen V, Tanner T, Kämppi A, Päkkilä J, Tjäderhane L, Patinen P. A methodological pilot study on oral health of young, healthy males. Dent Hypotheses. 2012 Nov;3(3):106-11. [doi: 10.4103/2155-8213.103928]

16. Humphris GM, Morrison T, Lindsay SJ. The Modified Dental Anxiety Scale: validation and United Kingdom norms. Community Dent Health. 1995 Sep;12(3):143-50. [Medline: 7584581]

17. Humphris GM, Freeman R, Campbell J, Tuutti H, D'Souza V. Further evidence for the reliability and validity of the Modified Dental Anxiety Scale. Int Dent J. 2000 Dec;50(6):367-70. [Medline: 11197195] [doi: 10.1111/j.1875-595X.2000.tb00570.x]

18. Luyk NH, Beck FM, Weaver JM. A visual analogue scale in the assessment of dental anxiety. Anesth Prog. 1988 MayJun;35(3):121-3. [Medline: 3166350] [PMC free article: 2168029] 
19. Pohjola V, Lahti S, Vehkalahti MM, Tolvanen M, Hausen H. Age-specific associations between dental fear and dental condition among adults in Finland. Acta Odontol Scand. 2008 Oct;66(5):278-85. [Medline: 18720054] [doi: $10.1080 / 00016350802293960$ ]

20. Eitner S, Wichmann M, Paulsen A, Holst S. Dental anxiety--an epidemiological study on its clinical correlation and effects on oral health. J Oral Rehabil. 2006 Aug;33(8):588-93. [Medline: 16856956] [doi: 10.1111/j.1365-2842.2005.01589.x]

21. Robinson PG, Acquah S, Gibson B. Drug users: oral health-related attitudes and behaviours. Br Dent J. 2005 Feb 26;198(4):219-24, discussion 214. [Medline: 15731805] [doi: 10.1038/sj.bdj.4812090]

22. Scully C. Drug effects on salivary glands: dry mouth. Oral Dis. 2003 Jul;9(4):165-76. [Medline: 12974516] [doi: 10.1034/j.1601-0825.2003.03967.x]

23. Pohjola V, Mattila AK, Joukamaa M, Lahti S. Anxiety and depressive disorders and dental fear among adults in Finland. Eur J Oral Sci. 2011 Feb;119(1):55-60. [Medline: 21244512] [doi: 10.1111/j.1600-0722.2010.00795.x]

24. Locker D, Poulton R, Thomson WM. Psychological disorders and dental anxiety in a young adult population. Community Dent Oral Epidemiol. 2001 Dec;29(6):456-63. [Medline: 11784289] [doi: 10.1034/j.1600-0528.2001.290607.x]

25. Fazel S, Hayes AJ, Bartellas K, Clerici M, Trestman R. Mental health of prisoners: prevalence, adverse outcomes, and interventions. Lancet Psychiatry. 2016 Sep;3(9):871-81. [Medline: 27426440] [doi: 10.1016/S2215-0366(16)30142-0]

26. Joukamaa M, Aarnio J, von Gruenewaldt V, Hakamäki S, Hypén K, Laurema H, Lintonen T, Mattila A, Tyni S, Vartiainen H, Viitanen P, Wuolijoki T. Rikosseuraamusasiakkaiden terveys, työkyky ja hoidon tarve. [Health, working capacity and need for treatment of criminal sanction clients]. Perustulosraportti. Rikosseuraamuslaitoksen julkaisuja 1/2010. Vammala: Vammalan Kirjapaino Oy. Finnish. [URL: https://www.rikosseuraamus.fi/material/attachments/rise/julkaisutrisenjulkaisusarja/6AqMACEr8/RISE_1_2010_Rikosseuraamusasiakkaiden_terveys_tyokyky_ja_hoidontarve.pdf]

27. Pohjola V, Mattila AK, Joukamaa M, Lahti S. Alcohol use disorder, smoking and dental fear among adults in Finland. Acta Odontol Scand. 2013 Mar;71(2):300-6. [Medline: 22545790] [doi: 10.3109/00016357.2012.680902]

28. Tanner T, Kämppi A, Päkkilä J, Järvelin MR, Patinen P, Tjäderhane L, Anttonen V. Association of smoking and snuffing with dental caries occurrence in a young male population in Finland: a cross-sectional study. Acta Odontol Scand. 2014 Nov;72(8):1017-24. [Medline: 25141188] [doi: 10.3109/00016357.2014.942877]

29. Taskinen H, Kankaala T, Rajavaara P, Pesonen P, Laitala ML, Anttonen V. Self-reported causes for referral to dental treatment under general anaesthesia (DGA): a cross-sectional survey. Eur Arch Paediatr Dent. 2014 Apr;15(2):105-12. [Medline: 23918236] [doi: 10.1007/s40368-013-0071-2]

\section{To cite this article:}

Vainionpää R, Pesonen P, Laitala ML, Pohjola V, Anttonen V.

Dental Fear and Dental Health and Attendance among Finnish Male Prisoners

J Oral Maxillofac Res 2019;10(4):e4

URL: http://www.ejomr.org/JOMR/archives/2019/4/e4/v10n4e4.pdf

doi: $10.5037 /$ jomr.2019.10404

Copyright (C) Vainionpää R, Pesonen P, Laitala ML, Pohjola V, Anttonen V. Published in the JOURNAL OF ORAL \& MAXILLOFACIAL RESEARCH (http://www.ejomr.org), 30 December 2019.

This is an open-access article, first published in the JOURNAL OF ORAL \& MAXILLOFACIAL RESEARCH, distributed under the terms of the Creative Commons Attribution-Noncommercial-No Derivative Works 3.0 Unported License, which permits unrestricted non-commercial use, distribution, and reproduction in any medium, provided the original work and is properly cited. The copyright, license information and link to the original publication on (http://www.ejomr.org) must be included. 